Vol. 1, No. 2, pp. 137-146, (December 2020)

DOI: 10.21608/aujes.2020.127569

Aswan University Journal of Environmental Studies (AUJES)

Online ISSN: 2735-4237, Print ISSN: 2735-4229

Journal homepage: https://aujes.journals.ekb.eg/

E-mail: AUJES@aswu.edu.eg

Original research

\title{
Improvement of Some Chemical and Electrical Properties of Aged Transformer Oil using Eco-Friendly Fillers
}

\author{
G. M. Taha ${ }^{a}$, L. S. Nasrat ${ }^{\mathrm{b}}$ and G. S. Younes ${ }^{\mathrm{c}^{*}}$ \\ ${ }^{a}$ Chemistry Department, Faculty of Science, Aswan university, Aswan, Egypt \\ ${ }^{b}$ Electrical Engineering Department, Faculty of Engineering, Aswan university, Aswan, Egypt \\ ${ }^{c}$ Hydro Plants Generation Company, Aswan, Egypt
}

Received: $25 / 8 / 2020$

Accepted: 16/10/2020

(C) Unit of Environmental Studies and Development, Aswan University

\begin{abstract}
:
Transformers are the main component in power generation industries and play a vital part in supplying electricity all over the world. Two main insulators are used in transformers, solid insulator or cellulosic paper and liquid insulator known as insulating oil or transformer oil. Transformer oil has the function of insulation and cooling as basic function also, it is used in suppressing electrical charge and preserving inner component of transformer against corrosion. During service oil deterioration take place under the impact of thermal and electrical stresses. Chemical composition of oil changes with formation of oxidation products and oil characteristics is no longer existing, hence, Transformer oil is monitored in terms of chemical, physical and electrical properties while dissolved gases is carried out by gas chromatography. After years in service, aging of transformer oil with formation of oxidation products is mandatory, looking for solutions able to regenerate oil and remove undesired products without being harmful to original composition of oil chains is required. Treatment of aged oil get attention recently with reclaiming by variety of chemical techniques and different materials for improvement of its properties and maintain these oils in operation for next years. This study represents reclaiming procedure by means of three eco-friendly inorganic fillers: Activated Bentonite (AB), Activated Carbon (AC) and Silica Fume (SF) which used in form of mixture fillers in the sequence of ( $A B+A C)$, $(\mathrm{AB}+\mathrm{SF})$ and $(\mathrm{SF}+\mathrm{AC})$. The main scope is reclaiming aged transformer oil and using mixture technique for efficacy of two fillers despite one. Three properties acidity as a chemical property, dissipation factor and breakdown voltage as electrical properties are tested for the series of mixtures, improvement was achieved providing an environmental reclaiming procedure. Best result in acidity is attributed to mixture $1: 5(\mathrm{AB}+\mathrm{SF})$ with $0.072 \mathrm{mg} \mathrm{KOH} / \mathrm{g}$ oil and enhancement percentage of $-30.8 \%$ while improvement in dissipation factor showed result of 0.039 and an enhancement of $61 \%$ for mixture 1:7 SF+AC. Breakdown voltage showed improvement of $122.9 \%$ of $78 \mathrm{KV} / 2.5 \mathrm{~mm}$ for mixtures $3: 1,5: 1$ and $7: 1(\mathrm{AB}+\mathrm{SF})$.
\end{abstract}

Keywords: Aged transformer oil; eco-friendly filler mixtures; Activated Bentonite; Activated carbon; Silica fume.

Corresponding authors*: E-mail addresses: ghadasol7282@gmail.com 


\section{1- INTRODUCTION}

Transformers form a critical highly loaded and expensive part of the electricity generation and distribution networks. Transformer oil or insulating oil consists of hydrocarbon chains which chemically break while in service due to chemical interactions with electrical and mechanical stresses causing oil deterioration. Breaking the chemical bonds with evolving of dissolved gases and formation of free radicals. Combination of free radicals with electrons form charge carrier radicals which increase dissipation factor value and could change the color of oil to dark followed by oil insulation failure (Fofana et al., 2009). It is important to supervise the function of transformer oil in service occasionally by testing chemical, physical and electrical properties to discover any kind of failures or even disturbances in performance early enough to manage it (IEC 60296, 2012). Failure of transformer oils with time and effort required for oil substitution makes power generation systems highly expensive on economic point of view (Fofana et al., 1999). Disposal of aged transformer oil has its environmental consequences, invalid aged transformer oil is environmentally harmful when leaked in water or soil as some transformer oils contain or may be cross contaminated by toxic additives such as PCB (poly chlorinated biphenyl). Many international convections forbid the usage of such additives in insulating oils with restricted terms in handling and selling any used oils containing PCBs, among those conventions is Stockholm convention in 2004. New studies approved that toxicity of PCBs lies in their damage effect to the reproductive, neurological and immune systems, also are known as carcinogenic compounds (Pelitli et al., 2015). These previous reasons were the base of new direction established by treatment of aged transformer oils via different techniques. Starting with original filtration process on site of transformer, the oil is first heated to $60-70{ }^{\circ} \mathrm{C}$ then passes through ionic column to reduce acidity followed by removal of suspended particles and sludge using means of filters and finally degassing and dehydration process for removal of dissolved gases and moisture (Salvi and Paranjape, 2017). One of the procedures used is mixing synthetic esters with transformer oils in different ratios with the aim of improving insulation properties of the mixtures (Perrier et al., 2006), others went to even using synthetic esters as an alternative to mineral insulating oils and the chemical and electrical tests of both were compared (Olawuni and Adejumobi, 2014). Chemical treatments using different techniques known as reclaiming process used also via the usage of surface-active fillers for the removal of undesired compounds and improvement of insulation properties. Nanoparticles shared as powerful active surface species in reclaiming aged transformer oils depending on its high surface area. $\mathrm{ZnO}$ nanoparticles were used in mixture of different concentrations to mineral oil and an observed enhancement in breakdown voltage of $63.5 \%$ is obtained (Ranjan et al., 2016). Vegetable oils are also in concern as an alternative or mixed with transformer oil, one of the vegetable oils suggested as an alternative for mineral transformer oil is soybean seed oil and measured properties were applicable to transformer oil specifications and conforming to international standards (Egbuna et al., 2016). Some researchers are considered in using chemical fillers and most popular are Bentonite clay which is one of the popular sorbent material used in chemical reclaiming of old transformer oil in filtration units for the purpose of removal of acidity, water content and impurities (Hafez et al., 2015). Activated Bentonite which used in many applications in industry and majorly used in treatment of aged transformer oil with satisfying results, bentonite clay was activated by addition of concentrated acid then filtered, dried and added to used transformer oil, improvement in chemical and electrical properties was obtained (Nasrat et al., 2011). This study focuses on reclaiming aged transformer oil via dual mixtures of three fillers, Activated Bentonite $(A B)$, Activated Carbon $(A C)$ and Silica Fume $(S F)$ to achieve the purpose of reclaiming treatment. 
Bentonite clay was activated by $2 \mathrm{~N}$ sulfuric acid (Moltlagh et al., 2011). The activation process is the attack of hydrogen ions from the acid to the aluminosilicate layers of bentonite clay, this attack changes the structure, chemical composition, and physical properties hence increasing adsorption capacity (Pande et al., 2011). Aged oil samples are chemically treated with these three eco-friendly fillers in dual mixture to establish the improvement of aged oil properties, best mixture and ratio for enhancement of each property.

\section{2- MATERIALS AND METHODS}

All the used chemicals and reagents were of analytical highly pure grade. Bi-distilled water was used in all solution preparations.

\subsection{Materials:}

Activated Bentonite:

Bentonite clay was collected from Kalabsha area, south Aswan, Aswan, Egypt. Bulk clay was grinded softly to particle size $<63 \mu \mathrm{m}$ then activated by $2 \mathrm{~N}$ of $\mathrm{H}_{2} \mathrm{SO}_{4}$, filtered and washed with bi-distilled water till neutralization, drying overnight at room temperature followed by drying at $70^{\circ} \mathrm{C}$ for 3 hours. Surface area for both bentonite clay and activated bentonite was measured, Results were 49.408 and $102.355 \mathrm{~m}^{2} / \mathrm{g}$, respectively. Pore volume developed from 0.087 to $0.149 \mathrm{cc} / \mathrm{g}$.

\section{Activated Carbon:}

Activated carbon was purchased from Merck, particle size $<63 \mu \mathrm{m}$.

Silica Fume:

Silica Fume, as industrial waste was collected from the Egyptian Company for Chemical Industries (KIMA), Aswan, Egypt, with particle size $<63 \mu \mathrm{m}$.

\subsection{Methods:}

Preparing a sample of filler mixture takes place by heating up a known volume $(400 \mathrm{ml})$ of aged oil sample to $70^{\circ} \mathrm{C}$, first filler dose is added and sample is stirred for 30 minutes, then the sample is reheated again to $70^{\circ} \mathrm{C}$ and the second filler dose is added. Stir the mixture for another 30 minutes then stand for overnight and filter using whatman filter paper 40. The addition of one filler then the other after stirring and heating give the first filler the opportunity for diffusion among the oil particles before addition of the other filler, this technique is required for better behavior of filler mixtures. Previous work used technique of mixing solid fillers together before addition to aged oil (Kumar et al., 2017) but in our case the improvement percentages in breakdown voltage were better. The resultant treated oil sample is heated to $90^{\circ} \mathrm{C}$ and cool to room temperature before testing, the steps are shown in figure (1).

\subsection{Equipment}

Acidity is measured according to the technical requirements of the standard method IEC 296. Standardization of all chemical reagents used in this test is referred to the international regulations.

Dissipation Factor (tan $\delta$ ) is measured according to the technical requirements of the standard method IEC 247. Equipment used is BAUR Dieltest DTL, Austria.

Breakdown Voltage is measured according to the technical requirements of the standard method of IEC 156. Equipment used is Foster Oiltest 90 Model, England. 


\section{3- RESULTS AND DISCUSSION}

Aged transformer Diala B oil used for this study was collected from upper Egypt electricity distribution company. Aged oil was primary tested for acidity, dissipation factor and breakdown voltage before preparation of sample mixtures. Table (1) show parameters of aged Diala B oil and its classification according to IEC 60422-2005. Aged transformer oils are followed up during service according to maintenance schedule and international standards therefore, all results are referred to specifications of the same international standard (IEC 60422-2005) for evaluation of enhancement degree and effect of reclaiming process.

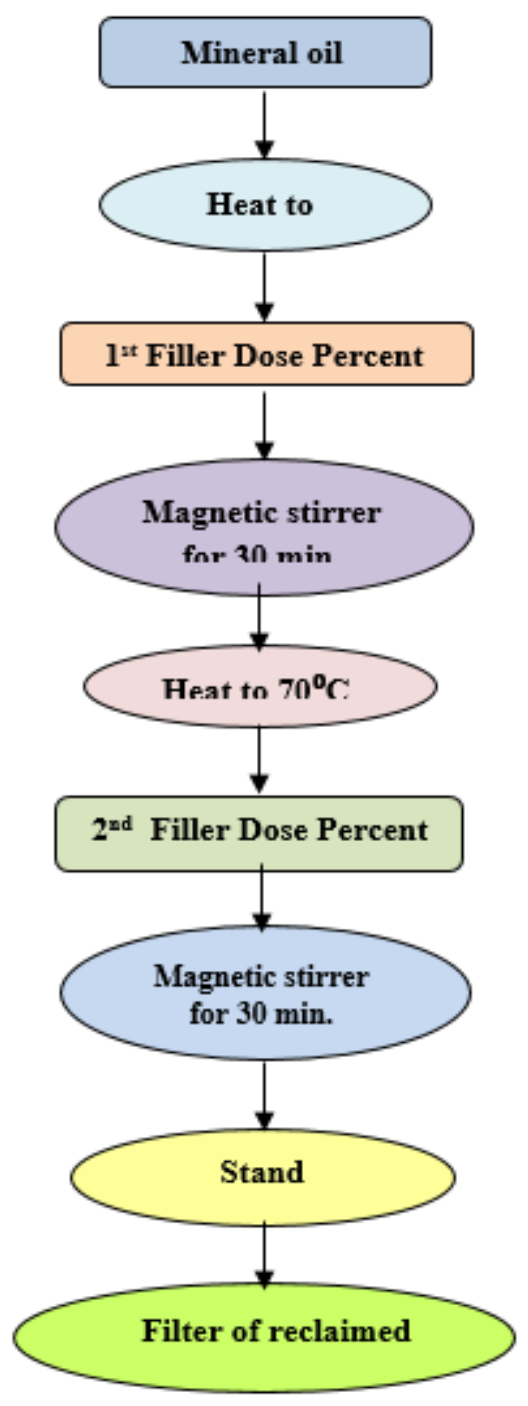

Fig. (1) Preparation of Oil Sample

\subsection{Acidity:}

Acid content in aged transformer oil is attributed to oxidation products which formed in oil during operation. The main aim of reclaiming treatment using filler mixtures is removal of oxidation products of acidic behavior leading to decrease total acidity of aged oil. Figures (2-a, 
b) reveal the reclaiming effect on acid content and an improvement was noticed for all filler mixtures. Best result for this test is $0.072 \mathrm{mg} \mathrm{KOH} / \mathrm{g}$ oil for filler mixture 1:5 activated bentonite+ silica fume $(\mathrm{AB}+\mathrm{SF})$ with enhancement percentage of $-30.8 \%$. Referring to IEC 60422 and results in table (2), result of aged oil is classified as "fair" (0.1-0.2 mg KOH/g oil) but after reclaiming using filler mixtures, the results turn to "good" $(<0.1 \mathrm{mg} \mathrm{KOH} / \mathrm{g}$ oil) classification.

Table (1). Parameters of Aged Transformer Oil

\begin{tabular}{c|c|c}
\hline Properties & Aged Oil & $\begin{array}{c}\text { Classification according } \\
\text { to IEC 60422 }\end{array}$ \\
\hline Acidity, mg KOH/1gm oil & 0.104 & Fair \\
\hline Viscosity at $40^{\circ} \mathrm{C}, \mathrm{C} . \mathrm{St}$ & 9.3 & - \\
\hline Flash Point PMCC, ${ }^{\circ} \mathrm{C}$ & 154 & - \\
\hline Dissipation Factor $(\mathrm{Tan} \delta)$ & 0.01 & Good \\
\hline Break down Voltage, $\mathrm{KV} / 2.5 \mathrm{~mm}$ & 35 & Poor \\
\hline
\end{tabular}

Table (2). Results of acidity with effect of Filler Mixtures

\begin{tabular}{|c|c|c|c|}
\hline Property & Mix & Ratio & Result \\
\hline \multirow{7}{*}{$\begin{array}{l}\text { Acidity } \mathrm{mg} \mathrm{KOH} / 1 \mathrm{~g} \text { oil } \\
\text { ( New } 0.008) \\
\text { ( Aged } 0.104 \text { ) }\end{array}$} & Act. Bentonite + Act. Carbon & $1: 1$ & 0.084 \\
\hline & Act. Bentonite + Act. Carbon & $1: 3$ & 0.081 \\
\hline & Act. Bentonite + Silica Fume & $1: 5$ & 0.072 \\
\hline & Act. Bentonite + Silica Fume & $1: 7$ & 0.075 \\
\hline & $\begin{array}{l}\text { Act. Bentonite + Act. Carbon } \\
\text { Silica Fume + Act. Carbon }\end{array}$ & $3: 1$ & 0.082 \\
\hline & Act. Bentonite + Act. Carbon & $5: 1$ & 0.081 \\
\hline & $\begin{array}{l}\text { Act. Bentonite + Act. Carbon } \\
\text { Act. Bentonite }+ \text { Silica Fume }\end{array}$ & $7: 1$ & 0.079 \\
\hline
\end{tabular}

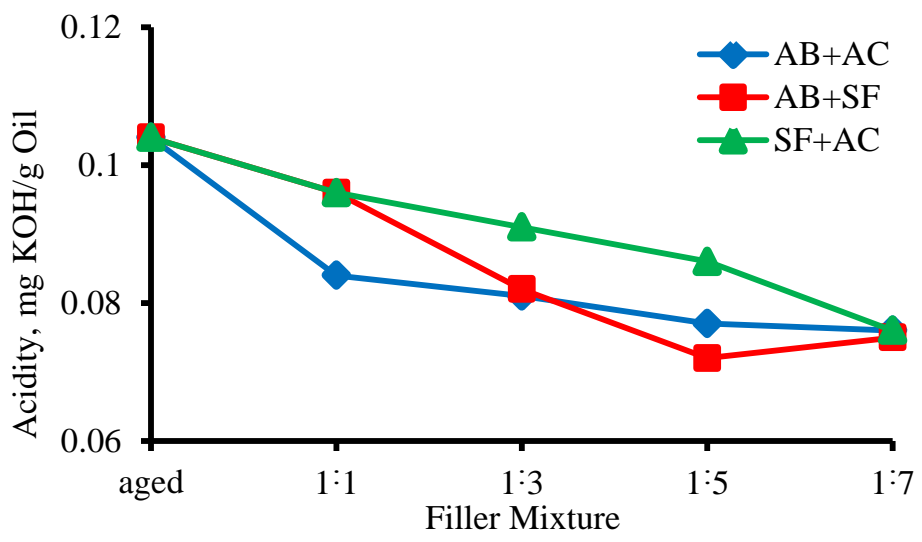

Fig. (2-a) Acidity of Filler Mixture 


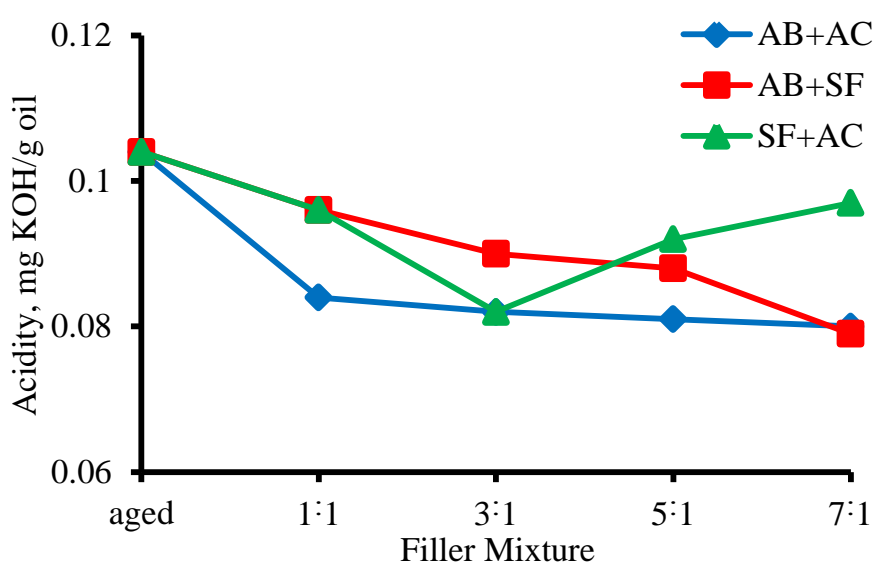

Fig. (2-b) Acidity of Filler Mixture

\subsection{Dissipation Factor:}

Dissipation Factor is the indicator of deterioration degree, contamination and presence of moisture in transformer oil. Results of filler mixture enhancement is shown in figures (3-a, b), disposal of deterioration compounds is translated in terms of decrease in dissipation factor. The behavior of filler mixtures show decrease in dissipation factor for all samples, filler mixture of $\mathrm{SF}+\mathrm{AC}$ showed the best behavior for dissipation factor with 0.0039 for filler mixture 1:7 silica fume+ activated carbon $(\mathrm{SF}+\mathrm{AC})$ and an enhancement percentage of $61 \%$. When referring to international standard of IEC 60422 and results shown in table (3), the result of aged oil is classified as "good" $(<0.1)$ and keep in "good" category after reclaiming process for all filler mixtures.

\subsection{Breakdown Voltage:}

The property of dielectric breakdown voltage is the measurement of electrical stress that an insulating oil can withstand without failure. Both figures of (4-a, b) show the corresponding breakdown voltage with filler mixtures, effect of filler mixtures on breakdown voltage appeared from first ratio. The best result achieved for filler mixture is $78 \mathrm{KV} / 2.5 \mathrm{~mm}$ with improvement percentage of $122.8 \%$. Figure (4-b) shows effect of filler mixture and best result is recorded for ratios 3:1, 5:1, 7:1 of mixture activated Bentonite+ silica fume $(\mathrm{AB}+\mathrm{SF})$ as a stability case in this property. Results in table (4) and According to international standard of IEC 60422, result of aged oil is classified as "poor" ( $<40 \mathrm{KV} / 2.5 \mathrm{~mm}$ ) while after reclaiming the results of all filler mixtures are classified as "good" $(>50 \mathrm{KV} / 2.5 \mathrm{~mm})$.

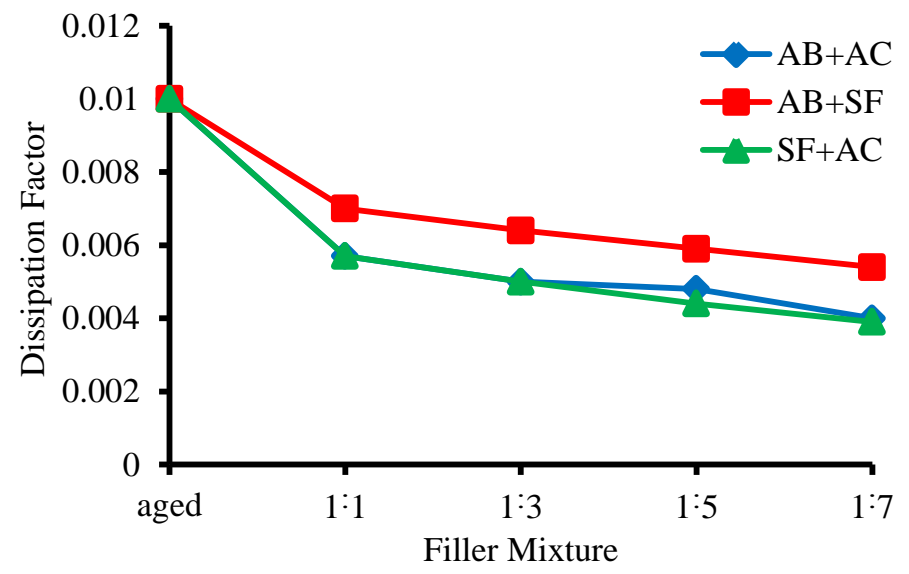


Fig. (3-a) Dissipation Factor of Filler Mixture

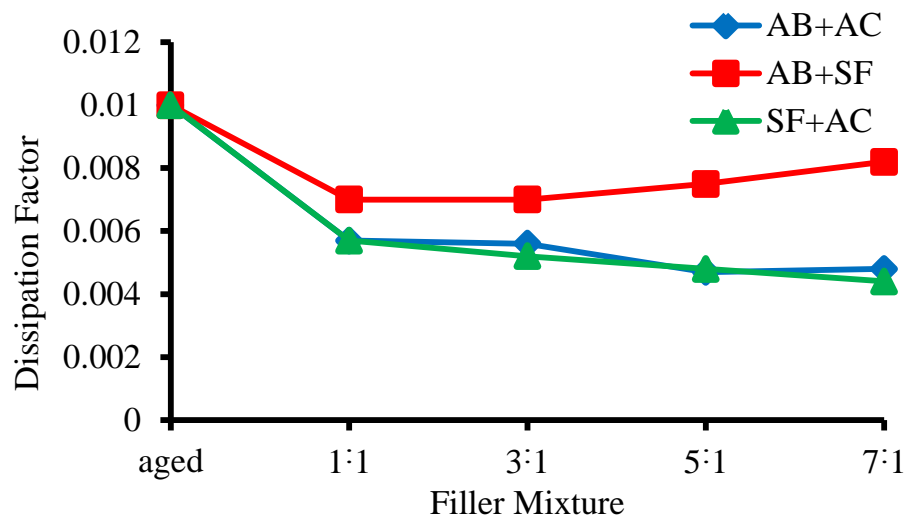

Fig. (3-b) Dissipation Factor of Filler Mixture

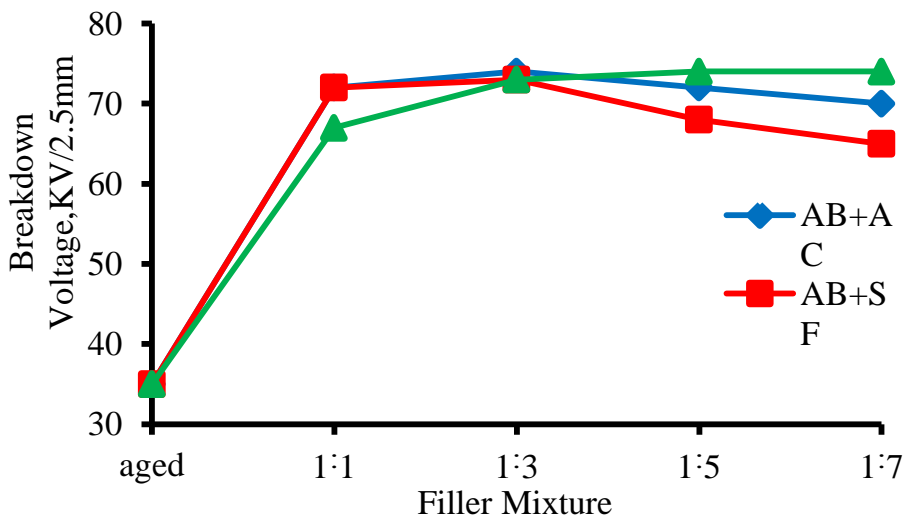

Fig. (4-a) Breakdown Voltage of Filler Mixture

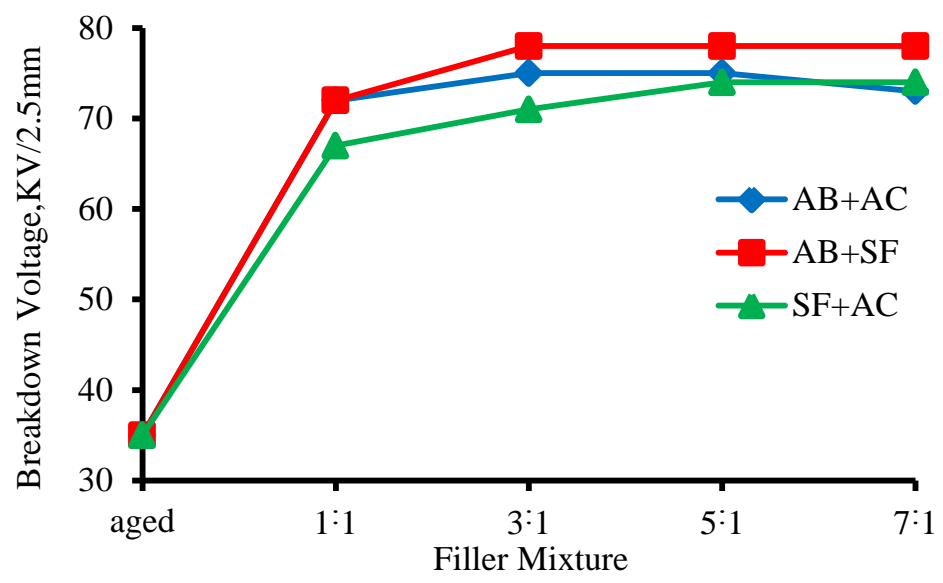

Fig. (4-b) Breakdown Voltage of Filler Mixture 
Aswan University Journal of Environmental Studies (AUJES) 1 (2), pp. 137-146, (2020).

Online ISSN: 2735-4237, Print: ISSN 2735-4229. https://aujes.journals.ekb.eg/

Table (3). Results of Dissipation Factor with Effect of Filler Mixtures

\begin{tabular}{|c|c|c|c|}
\hline Property & Mix. & Ratio & Result \\
\hline \multirow{7}{*}{$\begin{array}{c}\text { Dissipation Factor }(\tan \delta) \\
(\text { New } 0.0016) \\
(\text { Aged } 0.01)\end{array}$} & $\begin{array}{l}\text { Act. Bentonite + Act. Carbon } \\
\text { Silica Fume + Act. Carbon }\end{array}$ & 1:1 & 0.0057 \\
\hline & $\begin{array}{r}\text { Act. Bentonite + Act. Carbon } \\
\text { Silica Fume + Act. Carbon }\end{array}$ & $1: 3$ & 0.005 \\
\hline & Silica Fume + Act. Carbon & $1: 5$ & 0.0044 \\
\hline & Silica Fume + Act. Carbon & 1:7 & 0.0039 \\
\hline & Silica Fume + Act. Carbon & 3:1 & 0.0052 \\
\hline & Act. Bentonite + Act. Carbon & $5: 1$ & 0.0047 \\
\hline & Silica Fume + Act. Carbon & $7: 1$ & 0.0044 \\
\hline
\end{tabular}

Table (4). Results of Breakdown Voltage with Effect of Filler Mixtures

\begin{tabular}{|c|c|c|c|}
\hline Property & Mix. & Ratio & Result \\
\hline \multirow{7}{*}{$\begin{array}{c}\text { Breakdown Voltage (KV) } \\
(\text { New 60) } \\
(\text { Aged 35 ) }\end{array}$} & $\begin{array}{l}\text { Act. Bentonite + Act. Carbon } \\
\text { Act. Bentonite + Silica Fume }\end{array}$ & 1:1 & 72 \\
\hline & Act. Bentonite + Act. Carbon & $1: 3$ & 74 \\
\hline & Silica Fume + Act. Carbon & $1: 5$ & 74 \\
\hline & Silica Fume + Act. Carbon & $1: 7$ & 74 \\
\hline & Act. Bentonite + Silica Fume & $3: 1$ & 78 \\
\hline & Act. Bentonite + Silica Fume & $5: 1$ & 78 \\
\hline & Act. Bentonite + Silica Fume & $7: 1$ & 78 \\
\hline
\end{tabular}

Table (5). Best Results of filler Mixtures with acidity, Dissipation Factor and Breakdown Voltage

\begin{tabular}{|c|c|c|c|}
\hline Property & Mix & Ratio & Result \\
\hline $\begin{array}{c}\text { Acidity mg KOH/1 g oil } \\
\text { ( New 0.008) } \\
\text { ( Aged } 0.104 \text { ) }\end{array}$ & Act. Bentonite + Silica Fume & $1: 5$ & 0.072 \\
\hline $\begin{array}{c}\text { Dissipation Factor }(\tan \delta) \text { at } 90^{\circ} \mathrm{C} \\
(\text { New } 0.0016) \\
(\text { Aged } 0.01)\end{array}$ & Silica Fume + Act. Carbon & $1: 7$ & $\mathbf{0 . 0 0 3 9}$ \\
\hline $\begin{array}{c}\text { Breakdown Voltage KV/2.5 mm } \\
(\text { New 60 ) } \\
(\text { Aged 35 ) }\end{array}$ & Act. Bentonite + Silica Fume & $\begin{array}{l}3: 1 \\
5: 1 \\
7: 1\end{array}$ & 78 \\
\hline
\end{tabular}

\section{4- CONCLUSION}

Reclaiming of aged transformer oil is the main scope for this study by elimination of soluble and insoluble polar contaminates from oil. Dual mixtures for three different fillers in series of several ratios managed to enhance acidity, dissipation factor and breakdown voltage of aged Diala B oil, best results of three properties are shown in table (5). Acidity enhanced to a percentage of $-30.8 \%$, dissipation factor to percentage of $-61 \%$ while breakdown voltage enhanced to percentage of $122.8 \%$. The common filler among those achieved the best result is, 
silica fume (SF) a new promising filler with low cost and high performance in reclaiming treatment.

\section{5- ACKNOWLEDGEMENTS:}

The authors are grateful to great help of chemical laboratory at hydro plants generation company.

\section{6- REFERENCES}

Egbuna, S. O., Ude, O.C., Ude, C.N. (2016). Suitability of SoyaBean Seed Oil As Transformer Oil. International Journal of Engineering Sciences \& Research Technology, 5(10), 105-112.

Fofana I., Wasserberg V., Borsi H., Gockenbach E. (1999). The Electrical and Dielectrical Behavior of Mixed Insulation liquids for transformers, IEEE $13^{\text {th }}$ International Conference of Dielectric Liquids, 491- 494.

Fofana, I., Bouaicha, A., Farzaneh, M., Sabau, J., Bussieres, D., \& Robertson, E. B. (2010). Decay products in the liquid insulation of power transformers. IET Electric Power Applications, 4(3), 177-184.

Hafez A. I., Gerges N. S., El-nagar K. I., Mohamed S. E., Hashem A. I. (2015). Reclamation of Old Transformer Oil Using Kaolin Clay, International Journal of Advanced Scientific and Technical Research, 4(5), 752-769.

IEC 156 (1963). Method for The Determination of The Electric Strength of Insulating Oils, International Electrotechnical Commission IEC.

IEC 247 (1978). Measurement of Relative Permittivity, Dielectric Dissipation Factor (tan $\delta$ ) and d.c. Resistivity of Insulating Liquids, International Electrotechnical Commission IEC.

IEC 60296 (2012). Fluids for Electrotechnical Applications- Unused Mineral Insulating Oils for Transformers and Swithchgear, International Electrotechnical Commission IEC.

IEC 60422 (2005) Mineral Insulating Oils in Electrical Equipment- Supervision and Maintenance Guidance (2010), International Electrotechnical Commission IEC.

Kumar S. S., Iruthayarajan M. W., Bakrutheen M. (2017). Performance of Activated Bentonite and Carbon in Reclaiming the Properties of Used Mineral Oil, Journal of Electrical Engineering, 17(3), 407-417.

Motlagh M. M., Youzbashi A. A., Rigi Z. A. (2011). Effect of Acid Activation on Structural and Bleaching Properties of A Bentonite, Iranian Journal of Materials Science \& Engineering, 8(4), 50-56.

Nasrat L., Abdel-Wahab M., Ismail G (2011). Improvement of Used Transformer Oils with Activated Bentonite, Scientific Research, 3(6), 588-593.

Olawuni A., Adejumobi I. A. (2014). Breakdown Voltage Characteristics of Castor Oil as Alternative to Transformer insulating Oil, International Journal of Scientific Engineering and Research (IJSER), 2(4), 31-37.

Pande S., Bedre M. D., Madhusoodana C. D., Venkataramana A. (2011). Studies and Characterization of Bentonite Clay Obtained from Guibarga Karnataka Region, Material Science, 7(5), 297-301. 
Pelitli V., Dogan ö., Köroglu H. J. (2015). Transformer oils Potentials for PCBs Contamination, International Journal of Metallurgical \& Materials Engineering, 1, 1-8.

Perrier C., Beroual A., Bessede J-L. (2006). Improvement of Power Transformers by using Mixtures of Mineral Oil with Synthetic Esters, IEEE Transactions on Dielectrics and Electrical Insulation, 13(3), 556-564.

Ranjan N., Prasath R. T., Roy N. K. (2016). Aging Performance on Mineral Oil Using ZnO Nanofluids, International Journal of Innovations in Engineering and Technology, 6(3), 155162.

Salvi S., Paranjape A. P. (2017). Study of Transformer Oil Purification. SSRG International Journal of Electrical and Electronic Engineering, 4(3), 16-19. 